\title{
OESTROGEN PRODUCTION BY INDIVIDUAL FOLLICLES EXPLANTED FROM OVARIES OF SHEEP
}

\author{
R. M. MOOR \\ Agricultural Research Council, Unit of Reproductive Physiology and Biochemistry, \\ 307 Huntingdon Road, Cambridge CB3 0JQ
}

(Received 12th October 1972)

Ovarian follicles are a major site of oestrogen synthesis in sheep, but almost nothing is known about the relative contribution made by follicles of different sizes to the output of oestrogen at various stages of the reproductive cycle. To determine this, ovaries were dissected from sheep, all follicles over $2 \mathrm{~mm}$ in diameter were explanted separately as organ cultures and the daily production of oestrogen from each follicle was measured. This study was preceded by a series of preliminary experiments undertaken to define suitable conditions in which ovarian follicles would retain both their morphological integrity and steroidogenic capacity in culture.

The 224 follicles used in the preliminary series of experiments were explanted from the ovaries of seventeen sheep killed between the 2nd and 15th days of the oestrous cycle. A total of 218 follicles was used in the main experiment: 186 follicles were obtained from seventeen sheep during the oestrous cycle, seventeen follicles from two sheep at mid-pregnancy and fifteen follicles from two sheep during the anoestrous period. The follicles were dissected free of stromal tissue with watch-makers' forceps under a stereoscopic microscope and were cultured separately for 5 to 7 days.

A variety of different culture conditions were tested in the preliminary experiments but only the most salient results will be presented. Stainless steel grids provided excellent mechanical support for the follicles and no substantial advantage was obtained by interposing a layer of lens paper, rayon or Millipore membrane between the explant and the grid. Oestrogen production by follicles cultured as opened flat sheets of tissue was low, but unopened follicles (which had been punctured to release the follicular fluid) produced almost as high levels of oestrogen as the intact structures. Follicles maintained in a gas-phase containing 40 to $60 \%$ oxygen were morphologically and functionally well preserved (see Fainstat, 1968); a marked lowering or raising of the oxygen tension adversely affected the appearance and steroidogenic capacity of the follicles. No clear difference in oestrogen production or tissue survival was observed when the medium was changed daily as compared with changing it every 3rd day. This finding indicated that oestrogen secreted into the culture medium did not significantly inhibit the further synthesis of this steroid. Daily change of medium was adopted as a routine procedure to enable a more detailed analysis of oestrogen production to be made. 
In the main experiment, isolated follicles were cultured individually on stainless steel grids in 3-cm disposable Petri dishes (Sterilin Ltd, Richmond, U.K.). To each dish was added $2 \mathrm{ml}$ of a culture medium consisting of four parts M199 (Morgan, Morton and Parker Salts) and one part of fetal calf serum (Flow Laboratories, Irvine, U.K.). To each litre of the culture medium was added $56 \mathrm{mg}$ each of insulin, glutamine and ascorbic acid and $18 \mathrm{mg}$ gentamicin. The dishes were placed in an anaerobic jar, gassed with a mixture containing $45 \% \mathrm{O}_{2}, 5 \% \mathrm{CO}_{2}$ and $50 \% \mathrm{~N}_{2}$ and cultured at $37^{\circ} \mathrm{C}$.

Total unconjugated oestrogens were extracted from the culture medium with diethyl ether and measured by the radioimmunoassay procedure of Tillson, Thorneycroft, Abraham, Scaramuzzi \& Caldwell (1971) using an antiserum prepared against $17 \beta$-oestradiol. The results were corrected for procedural losses.

The size distribution of follicles explanted from sheep during the cycle, in pregnancy and during the anoestrous period was similar and confirmed the observations of Brand (1970). An average of 1.1 large follicles (greater than $4.5 \mathrm{~mm}$ diameter), 0.9 medium-sized follicles ( 3.1 to $4.5 \mathrm{~mm}$ diameter) and 8.3 small follicles ( 2.0 to $3.0 \mathrm{~mm}$ diameter) was dissected from each sheep.

The results obtained from the steroid analyses showed clearly that the one or two large follicles obtained from each sheep were highly active secretors of steroid hormones. The total output of oestrogen and the pattern in which it was secreted was markedly affected by the stage of the cycle at which the large follicles were explanted. Most large follicles explanted before the onset of oestrus secreted high levels of oestrogen in culture, the mean daily output being $314.9 \pm 25.0 \mathrm{ng}$; in $69 \%$ of these follicles, more than $400 \mathrm{ng}$ oestrogen were secreted on one or more days. When large follicles were explanted at oestrus, the amount of oestrogen produced in culture was much lower. The mean daily output from oestrous follicles was $29.4 \pm 9.8 \mathrm{ng} ; 75 \%$ of these follicles never produced more than $50 \mathrm{ng}$ oestrogen on any one day. It is noteworthy that the large follicles explanted at oestrus showed clear histological signs of luteinization at the end of the culture period. Preliminary analyses indicated that the luteinized follicles secreted progesterone at a level often in excess of $2 \mu \mathrm{g} / \mathrm{day}$.

The low levels of oestrogen secreted into the culture medium by the small and medium-sized follicles were in striking contrast to the high levels secreted by the large follicles. The output of oestrogen by small and medium-sized follicles, was, moreover, not significantly affected by the stage of the cycle at which they were explanted. The mean daily output of oestrogen by all small follicles was $18.8 \pm 2.2 \mathrm{ng}$; follicles under $3.0 \mathrm{~mm}$ in diameter can, therefore, probably be regarded as predominantly inactive. Medium-sized follicles were similarly relatively inactive; the mean daily output of oestrogen from these follicles was $38 \cdot 6 \pm 6 \cdot 4 \mathrm{ng}$.

The levels of oestrogen secreted by follicles explanted from pregnant and anoestrous sheep were similar to the levels secreted by follicles explanted at mid-cycle. High levels of oestrogen were produced by large follicles in culture; small and medium-sized follicles secreted low levels of oestrogen throughout the culture period.

Since the most dramatic change in oestrogen secretion in vivo occurs during 
the last 3 days of the cycle, it was of interest to examine the pattern of secretion of the large follicles explanted on these days. The results are shown in Text-fig. la to c. For comparison, the curve (Text-fig. ld) showing the low mean daily oestrogen production of all follicles under $4.5 \mathrm{~mm}$ in diameter is also included.

When large follicles were explanted on Day 14, the daily production of oestrogen rose over the first 2 days in culture and then declined slowly. This pattern of secretion is similar to that found in sheep in vivo by Cox, Mattner \& Thorburn (1971) except that the decline in oestrogen secretion in culture was more gradual than in vivo. As might be expected, follicles explanted on Day 15 have a lower mean daily oestrogen production than those explanted on Day 14. Oestrogen production by follicles explanted at oestrus was even lower and dropped rapidly in culture to insignificant levels.

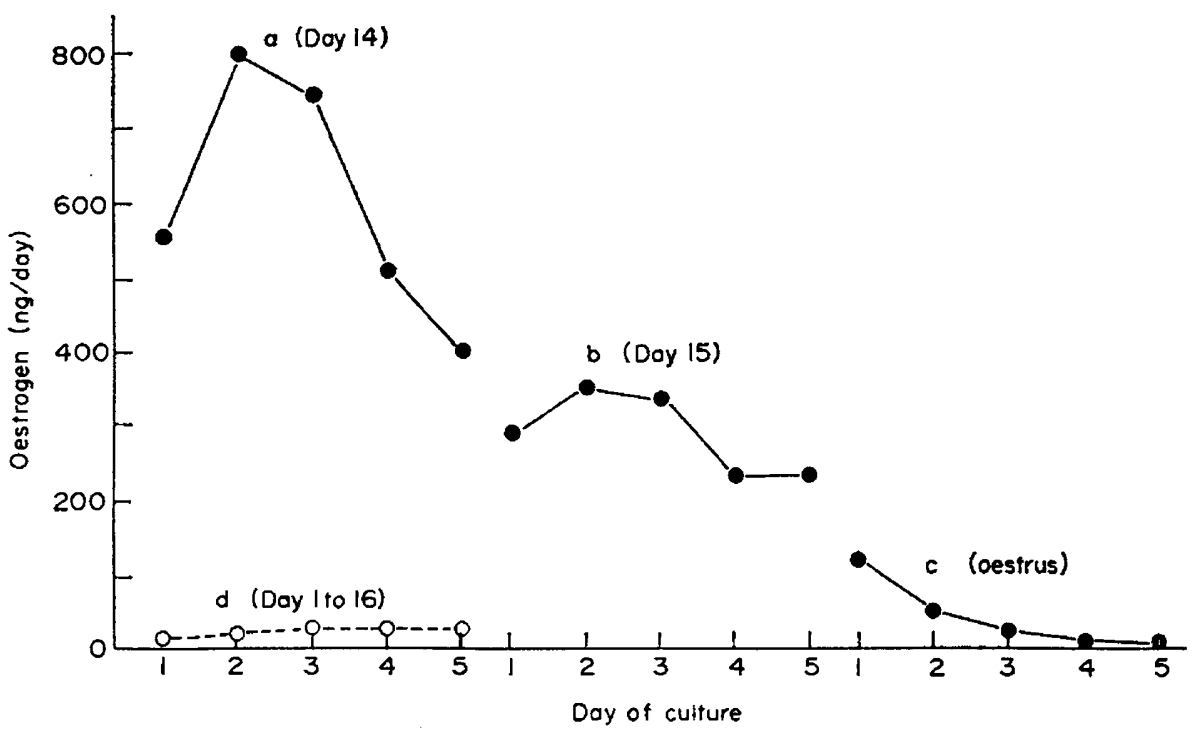

TEXT-FIG. 1. Mean daily oestrogen production by large follicles (greater than $4.5 \mathrm{~mm}$ diameter) explanted from sheep on Day 14 (a), Day 15 (b) and at oestrus (c). The mean daily oestrogen production by all follicles less than $4.5 \mathrm{~mm}$ in diameter is also shown (d).

It is well established that hypophysectomy leads to the rapid and total degeneration of the entire population of Graafian follicles (Smith, 1939). It is, therefore, remarkable that follicles maintained in vitro, in the apparent absence of gonadotrophins, retained their morphological integrity and functional capacity for extended periods of time. The calf serum component in the culture medium was a possible source of gonadotrophin available to the cultured follicles but tests of the serum, using the radioimmunoassay procedure, did not detect the presence of any LH. Furthermore, it was found that the calf serum could be replaced by recrystallized bovine serum albumin without adversely affecting the functional capacity of the cultured follicles.

The present experiments, in conjunction with the results of the earlier histochemical studies of Moor, Hay \& Caldwell (1971), provide evidence that only 
the largest one or two ovarian follicles in each sheep have the ability to secrete significant amounts of oestrogen. The pattern of oestrogen production by large follicles in vitro has been shown to be similar in most respects to that observed in vivo, even though the cultured follicles were denied further gonadotrophic support. This suggests that a major rôle of gonadotrophic hormones is to influence the largest follicle to secrete oestrogen in a characteristic pattern; an analogous process, the hormonal activation of the granulosa cells to secrete progesterone, has already been postulated by Channing (1970). Once the follicle has become activated, oestrogen can be secreted in the absence of further gonadotrophic support. At the end of the period of oestrogen secretion, the follicles appear to become dependent upon a further period of gonadotrophic regulation; the elevated levels of circulating LH at this stage act back on the follicle to terminate oestrogen production in rats (Hori, Ide \& Miyaki, 1969) and sheep (R. M. Moor, unpublished observations).

The author wishes to acknowledge with appreciation the skilled technical assistance of Miss Yvonne L. Baglin and Mr D. Green. I am grateful to Dr Mary F. Hay and Professor T. R. R. Mann for their generous help during the preparation of this paper.

\section{REFERENCES}

BRAND, A. (1970) Enkele micromorfologische en biochemische aspecten van de ovaria van het Texelse schaap tijdens het oestrusseizoen. Thesis, University of Utrecht.

Channing, G. P. (1970) Influence of the in vivo and in vitro hormonal environment upon luteinization of granulosa cells in tissue culture. Recent Prog. Horm. Res. 26, 589.

Cox, R. J., MATTNer, P. E. \& ThorbuRN, G. D. (1971) Changes in ovarian secretion of oestradiol-17 $\beta$ around oestrus in the sheep. F. Endocr. 49, 345.

FaINSTAT, T. (1968) Organ culture of postnatal rat ovaries in chemically defined media. Fert. Steril. $19,317$.

HoRI, T., IDE, M. \& MrYAKI, T. (1969) Ovarian oestrogen secretion during the estrous cycle under the influence of exogenous gonadotrophins in rats. Endocr. jap. 15, 215.

Moor, R. M., HAX, M. F. \& Galdweld, B. V. (1971) The sheep follicle: relation between sites of steroid dehydrogenase activity, gonadotrophic stimulation and steroid production. $\mathcal{F}$. Reprod. Fert. 27, 484.

SMrTH, P. E. (1939) The effect on the gonads of the ablation and implantation of the hypophysis and the potency of the hypophysis under various conditions. In: Sex and Internal Secretions, p. 931. Ed. E. Allen. Baillière, Tindall \& Gox, London.

Tillson, S. A., Thorneycroft, D. H., Abraham, G. E., Scaramuzzi, R. J. \& Caldwell, B. V. (1971) Solid phase radio-immunoassay of steroids. In: Immunological Methods in Steroid Determinations. Eds F. G. Peron and B. V. Caldwell. Appleton Century Crofts, New York. 